1 Hall NF, Gale CR, Syddall H, Phillips DI, Martyn CN. Risk of macular degeneration in users of statins: cross sectional study. BMJ 2001;323:375-6

2 McCarty CA, Mukesh BN, Guymer RH, Baird PN, Taylor HR. Cholesterol-lowering medications reduce the risk of age-related maculopathy progression. Med J Aust 2001;175:340.

3 Arnold JJ, Sarks SH. Extracts from "clinical evidence": age related macular degeneration. BMJ 2000;321:741-4.

4 Bird AC, Bressler NM, Bressler SB, Chisholm IH, Coscas G, Davis MD, et al, for the International ARM Epidemiological Study Group. An international classification and grading system for age-related maculopathy and age-related macular degeneration. Surv Ophthalmol 1995;39:367-74.

5 In t' Veld BA, Ruitenberg A, Hofman A, Launer LJ, van Duijn CM, Stijnen T, et al. Nonsteroidal anti-inflammatory drugs and the risk of Alzheimer's disease. N Engl J Med 2001;345:1515-21.

(Accepted 20 August 2002)

RESEARCH POINTERS

\title{
Mortality from cardiovascular disease more than 10 years after radiotherapy for breast cancer: nationwide cohort study of 90000 Swedish women
}

Increased cardiovascular mortality more than 10 years after diagnosis of breast cancer is compatible with radiotherapy causing a substantial hazard

Clinical Trial Service Unit and Epidemiological Studies Unit, Radcliffe Infirmary, Oxford OX2 6HE

Sarah Darby professor

Paul McGale statistician Richard Peto codirector

Department of Medical

Epidemiology, Karolinska Institute, 17177 Stockholm, Sweden

Fredrik Granath statistician

Per Hall

professor

Department of Medicine,

Karolinska Institute Anders Ekbom professor

Correspondence to: S Darby

sarah.darby@ ctsu.ox.ac.uk

BMJ 2003;326:256-7
During radiotherapy for breast cancer there is often some irradiation of the heart and major blood vessels, which could increase cardiovascular mortality many years later. ${ }^{1-3}$ The dose of radiation to the heart is generally higher when the left rather than the right breast is affected. Therefore, indirect evidence on the magnitude of any risk is available where the tumour laterality (left or right breast) can be linked to subsequent cardiovascular mortality. ${ }^{12}$ Studies of the survivors of the atomic bombing of Japan who received single doses to the whole body of 0-4 Gy show that the cardiovascular disease risk is dose related and increases by about $14 \%$ per gray. ${ }^{4}$

\section{Participants, methods, and results}

Since 1970, the nationwide Swedish cancer registry has recorded the laterality of breast cancers but not the use of radiotherapy. Unpublished data from regional Swedish registries suggest that about $30 \%$ of women with early breast cancer during the 1970s and early ' 80 s received radiotherapy. We linked registry records (1970-96) with national mortality records. The study was approved by the ethics committee of the Karolinska Institute.

After we excluded women whose cancer was diagnosed at autopsy or outside Sweden and those with previously registered cancers (except squamous cell skin cancer), 89407 women aged 18-79 with unilateral breast cancer remained. We stratified analyses of subsequent mortality in groups of five years by calendar year of diagnosis, time since diagnosis, and age at diagnosis. Stratification by age was necessary because the proportion of left sided tumours increases with age. ${ }^{5}$ Each woman's contribution to the person years at risk ran from the date of diagnosis until her date of death, date of emigration, 100th birthday, or 1 January 1997, whichever was earliest. We used Poisson regression to calculate mortality ratios, left versus right, from the numbers of deaths and person years. Ratios greater than one indicate greater mortality in women with left sided tumours than in women with right sided tumours.

Mortality from breast cancer was identical in women with left sided or right sided tumours (table). Mortality from cardiovascular diseases was higher in women with left sided tumours. Little excess occurred in the first 10 years after diagnosis (mortality ratio $1.01 ; 95 \%$ confidence interval 0.96 to 1.07 ), but later the ratio was 1.10 ( 1.03 to $1.18 ; \mathrm{P}=0.004), 1.13$ ( 1.03 to $1.25 ; \mathrm{P}=0.01$ ) for ischaemic heart disease (half of all cardiovascular mortality), and 1.08 (0.98 to 1.18) for other cardiovascular deaths (about $30 \%$ of which

Mortality ratio for women with left sided breast cancer versus women with right sided breast cancer during and after the first 10 years from diagnosis of breast cancer among 89407 women registered during 1970-96 at the Swedish cancer registry

\begin{tabular}{|c|c|c|c|c|c|}
\hline \multirow{2}{*}{ Cause of death (ICD-9 code) } & \multirow{2}{*}{$\begin{array}{c}\text { All years } \\
\text { Mortality ratio, left } \\
\text { versus right }(95 \% \mathrm{CI})\end{array}$} & \multicolumn{2}{|r|}{$<10$ years } & \multicolumn{2}{|c|}{$\geqslant 10$ years } \\
\hline & & $\begin{array}{l}\text { No of } \\
\text { deaths }\end{array}$ & $\begin{array}{c}\text { Mortality ratio, left } \\
\text { versus right ( } 95 \% \mathrm{Cl})\end{array}$ & $\begin{array}{l}\text { No of } \\
\text { deaths }\end{array}$ & $\begin{array}{c}\text { Mortality ratio, left } \\
\text { versus right }(95 \% \mathrm{CI})\end{array}$ \\
\hline Breast cancer (174) & $1.00(0.98$ to 1.03$)$ & 21196 & $1.00(0.97$ to 1.03$)$ & 2714 & 1.00 (0.93 to 1.08$)$ \\
\hline \multicolumn{6}{|l|}{ Cardiovascular diseases: } \\
\hline All $(390-459,785$, and 798$)$ & $1.04(1.00 \text { to } 1.09)^{*}$ & 5739 & $1.01(0.96$ to 1.07$)$ & 3426 & $1.10(1.03$ to 1.18$) \dagger$ \\
\hline Ischaemic heart disease (410-414) & 1.06 (1.00 to 1.12$) \ddagger$ & 3078 & $1.02(0.95$ to 1.10$)$ & 1613 & $1.13(1.03$ to 1.25$) \S$ \\
\hline Other cardiovascular diseases & $1.03(0.97$ to 1.09$)$ & 2661 & $1.00(0.93$ to 1.08$)$ & 1813 & 1.08 (0.98 to 1.18$)$ \\
\hline Remaining causes & 0.97 (0.93 to 1.02) & 4446 & 0.96 (0.90 to 1.01$)$ & 2602 & 1.00 (0.92 to 1.07$)$ \\
\hline
\end{tabular}

CD-9=International classification of diseases, ninth revision. 
probably involved heart disease). For the remaining causes, mortality in women with left sided tumours did not differ significantly from that in women with right sided tumours.

Most of the late cardiovascular deaths involved women treated for breast cancer in the 1970s, and improvements in radiotherapy techniques since then have tended to reduce radiation dose to the heart. For women treated in the 1980 s, however, the cardiovascular ratio, left versus right, was still 1.11 but with a wide $95 \%$ confidence interval ( 0.95 to 1.29 ).

\section{Comment}

A mortality ratio, left versus right, of 1.10 for cardiovascular disease more than 10 years after diagnosis of breast cancer is compatible with a substantial hazard among some of those actually irradiated. For example, if about $30 \%$ of women surviving 10 years after breast cancer had been irradiated then a cardiovascular mortality ratio of 1.10 in all women and 1.00 in unirradiated women would suggest a ratio of 1.33 in those irradiated. This could be produced by a $60 \%$ increase in late cardiovascular mortality after irradiation for a left sided tumour and a 20\% increase after irradiation for a right sided tumour. The confidence interval for the observed ratio of 1.10 is, however, wide, so the true cardiovascular hazard from radiotherapy in the $1970 \mathrm{~s}$ and ' 80 s remains uncertain.

Contributors: The study was conceived and designed by PH, SD, $\mathrm{AE}$, and FG. The statistical analysis was designed by $\mathrm{SD}$ and PMcG and done by PMcG. All authors contributed to the interpretation of the results and the preparation of the manuscript. $\mathrm{PH}$ is guarantor for the data; $\mathrm{SD}$ and $\mathrm{PMcG}$ are guarantors for the statistical analysis.

Funding: Clinical Trial Service Unit (SD, PMcG, and RP) supported by Cancer Research UK, the Medical Research Council, and the British Heart Foundation. Karolinska Institute (FG, AE, and PH) supported by independent Swedish research foundations, government sources, and the European Union.

Competing interests: None declared.

1 Paszat L, Mackillop WJ, Groome PA, Boyd C, Schulze K, Holowaty F Mortality from myocardial infarction after adjuvant radiotherapy for breast cancer in the surveillance, epidemiology and end-results cancer registries. J Clin Oncol 1998;16:2625-31.

2 Rutqvist LE, Johansson $\mathrm{H}$. Mortality by laterality of the primary tumour among 55000 breast cancer patients from the Swedish Cancer Registry. Br J Cancer 1990;61:866-8.

3 Early breast cancer trialists' collaborative group (EBCTCG). Favourable and unfavourable effects on long-term survival of radiotherapy for early breast cancer: an overview of the randomised trials. Lancet 2000;355:1757-70.

4 Shimizu Y, Pierce DA, Preston DL, Mabuchi K. Studies of the mortality of atomic bomb survivors: non-cancer mortality 1950-1990. Radiat Res 1999;152:374-89. (Report 12, part 11.)

5 Weiss HA, Devesa SS, Brinton LA. Laterality of breast cancer in the United States. Cancer Causes Control 1996;7:539-43.

(Accepted 24 July 2002)

\section{Drug points}

Thromboembolism associated with the new contraceptive Yasmin

Kees van Grootheest, Tom Vrieling

Our centre, the Dutch spontaneous reporting system for adverse drug reactions, recently received five reports of thromboembolism as a suspected adverse drug reaction to the new oral contraceptive Yasmin (ethinylestradiol and drospirenone).

A 17 year old woman suddenly collapsed and died after taking the contraceptive for six months. Autopsy showed that she had had a massive pulmonary embolism. No obvious risk factors for thromboembolism, such as smoking, a period of long immobilisation, air flights, or concomitant medication, were evident. ${ }^{1}$ Because she died suddenly no blood sample was taken. Blood taken from her parents did not test positive for any of the known risk factors: concentrations of protein $\mathrm{C}$ and antithrombin III were normal. The activated partial thromboplastin time and partial thromboplastin time were normal, and the existence of factor $\mathrm{V}$ Leiden mutation was excluded.

A 28 year old woman changed her oral contraceptive from ethinylestradiol with desogestrel (Marvelon) to ethinylestradiol with drospirenone. Four months later she had thrombosis in one leg and was treated with acenocoumarol. Risk factors or concomitant drugs were unknown.

Another patient, a 45 year old woman, had deep vein thrombosis in one leg after taking ethinylestradiol with drospirenone for two months, as did a 50 year old woman who took the contraceptive for three months.
A 35 year old woman had pulmonary thrombosis 17 days after she started taking the contraceptive. She had given birth four months earlier.

Ethinylestradiol with drospirenone has been approved as an oral contraceptive in all European Union countries since 2000 and has recently been launched in the United Kingdom. ${ }^{2}$ The public assessment report of the contraceptive gives only one suspected case of pulmonary embolism but also says that the number of cases in the preregistration studies are too low for a reliable conclusion on this matter. ${ }^{3}$

The risk of thromboembolism for women using the third generation (combined) pill has long been debated. Physicians therefore may prefer a new type of combined pill, like ethinylestradiol with drospirenone, assuming that these are safer. However, an association of these drugs with a lower risk of thromboembolism has not been proved by research, and our cases show that newer contraceptive pills may have a risk of thromboembolism. At present, insufficient data on the superiority of ethinylestradiol with drospirenone are available.

Funding: None.

Competing interests: None declared.

1 Winkler UH. Oral contraception in women at risk of venous disease. Gynaecol Forum 2001;6:23-8.

2 Sheldon T. Dutch GPs warned against new contraceptive pill. BMJ 2002;324:869

3 Official site of Dutch medicines evaluation board. www.cbg-meb.nl/nl/docs/ gnsmiddl/par-yasmin.pdf (accessed 21 October 2002).
Netherlands Pharmacovigilance Centre Lareb, Goudsbloemvallei 7, $5237 \mathrm{MH}$

's-Hertogenbosch, Netherlands

Tom Vrieling Kees van

Grootheest

Correspondence to: $\mathrm{K}$ van Grootheest ac.vangrootheest@ lareb.nl

BMJ 2003;326:257 